\title{
Pietas y simulación en la ofrenda privada romana
}

\author{
Diana Segarra Crespo*
}

\begin{abstract}
Este artículo ofrece una interpretación nueva sobre las substituciones sacrificiales partiendo de los pasajes de Serv. Aen. II.116 y IV.512 y utilizando el método comparativo. El análisis conjunto de diversas fuentes del mundo antiguo y de la documentación etnográfica relativa a estas prácticas ilustra la tipologia de las substituciones.

This article offers a new interpretation of the substitutions in sacrificial context starting from Serv. Aen. II.116 and IV.512 and using the comparative method. The analysis of data supplied by different sources of Ancient World beside the ethnographic documentation about these practices makes clear the typology of substitutions.
\end{abstract}

"Si no poseéis incienso, encended antorchas resinosas: a la bondadosa Ceres le complacen las pequeñas dádivas con tal de que sean piadosas" '. La posibilidad de substitución en este género aromático de la ofrenda romana se confiaba, pues, a la intención honesta del ofrecimiento personal que, en la práctica, se traducía en el ahorro evidente del coste de un producto importado, como era el incienso, ampliamente requerido en los usos cultuales romanos. Pero el autor de los Fastos no pretendía señalar o sugerir un subterfugio posible, para los menos pudientes, en el cumplimiento ritual sino que se hacía eco de una conocida corriente de pensamiento que propugnaba la "rusticidad" y la "modestia" en la ofrenda como pautas del comportamiento cultual correcto y, además, agradable a los dioses ${ }^{2}$. Ciertamente, el ideal de la paupertas - que explicaba la elección y la valoración de lo rural- impregnaría también los usos cultuales romanos de una cierta época en el sentido de una sencillez que, sin

* Este artículo está dedicado a WALTER BeVIgnANI.

Ov. fast. IV.410-411; cfr. Teofrasto apud Porph. Abst. II.15.3.

Sobre el uso del incienso en el culto vid. Arnob. nat. VII.148. Véase también n. 4. 
embargo, acabará por ser un "ofrecemos humildes inciensos con pobres ritos» ${ }^{3}$, pura elaboración literaria, pura poesía.

La base ideológica de tal comportamiento religioso no era, evidentemente, el modo de hacer de los pobres sino los usos sobrios de los antepasados, esfera de tiempo y de tradición cultual no contaminada - según la defensa posterior- por los lujos y las riquezas o por lo cruento en el ofrecimiento ${ }^{4}$. Así, la mítica frugalidad vegetal en los sacrificios era, al mismo tiempo que honesta, "poco costosa»: a la época de Rómulo o a la de Numa se atribuian tales consideraciones sobre la modestia religiosa como punto de referencia para un tiempo histórico en el que no pasaba de ser una recomendación (aun ciertamente prestigiada) la vigilancia del gasto en el ofrecimiento y, quizá también, su honestidad ${ }^{5}$.

La existencia de este topos sugiere el estudio de la posibilidad histórico-religiosa de un ahorro efectivo en la ofrenda privada a pesar de la rigidez de las prescripciones rituales romanas y, consecuentemente, el de la posibilidad de la aceptación y validez de la substitución de la ofrenda prescrita por algo de menor valor. En el caso de los no pudientes la substitución se operaría a la medida de sus posibilidades económicas y, por ello, a la noción de ahorro se deberá añadir el motivo de una verdadera imposibilidad en el cumplimiento de las prescripciones rituales.

Junto al ideal de la paupertas, existía -también como topos literariola concepción de pauperis omne nefas ${ }^{6}$ que sitúa en su justa consideración la actitud real ante este comportamiento religioso "modesto": se trataba de la imitación de una sencillez ideal (la mítica, la de los antepasados) y no del resultado - más o menos semejante- de una constricción a la reducción del valor de la ofrenda por falta de medios que podría ser nefasta. En todo caso, se podría hacer valer una mera lógica económica de los recursos disponibles, tal y como atestiguan las fuentes latinas, siendo una privación personal de una parte escogida de ellos (a través de la

\footnotetext{
3 Prop. II.10.24.

4 D.H. I.88.1, II.23.4-5 y cfr. II.25.2; Ov. fast. I.335-458, II.535-542, IV.393-412, 744 y met. XV.96; Tib.II.1, I.1.37-40, 10.19-24; Cic. leg. II.19 y 25; Plu. Num. 8.15 y Rom. 12.1. G. Piccaluga, Terminus. I segni di confine nella religione romana, Roma, 1974, 293-308. W. BURKERT, Homo Necans. Antropologia del sacrificio cruento nella Grecia antica, Turín, 1981, 212, n. 36.

5 D.H. 1.88.1; Plu. Num. 8.15. Vid. Plin. nat. XXXII.20 y XIV.88. Para la comparación entre la riqueza y el bienestar de la época y la sencillez en la ofrenda, véanse Cic. leg. II.45; Plin. nat. XXXV.158 o Ath. VI.274 a-c y 275 b.

6 Anth. 1.21.174: G. Focardi, "Pauperis omne nefas. Contributo per la ricostruzione di un topos", Sileno 14, 1988, 73-98; vid. F. Della Corte (ed.), Tibullo. Le Elegie, Milán 1989, 2ª ed., 135, n. 78 .
} 
adquisición o del patrimonio) la base de la ofrenda privada (por ejemplo, sobre la protección del patrimonio ganadero de una frecuencia o excesivo gasto en víctimas para el sacrificio ${ }^{7}$, o respecto de su elección en el mercado, basada en una menor exigencia respecto del parámetro de perfección prescrito por los rituales, lo que determinaba su menor cuantía en el precio ${ }^{8}$ ).

Las prescripciones rituales eran rígidas, inmutables, y contra su violación se alzaban voces de autoridad como Tito Livio, Varrón, Plinio, Cicerón, Arnobio..., pero junto a ellas se destacan los testimonios de ciertas irregularidades o desviaciones de la norma: en la época de Plinio se seguía usando en los rituales la hierba sabina en substitución del incienso ${ }^{9}$; una solución, quizá doméstica, de un gasto y en el extremo inferior de la escala de las posibles substituciones en la ofrenda si se consideran, por ejemplo, los testimonios sobre el robo del oro del Capitolio y su substitución por una cantidad idéntica de cobre dorado, perpetrados por César, o sobre la similar acción de Vitelio, que substrajo las ofrendas y los ornamentos de los templos de Roma colocando cobre y estaño en lugar del oro y la plata ${ }^{10}$. Se trataba, pues, de unos robos sacrílegos y de fraudes quizá "mitigados" por esa substitución de elementos que respetaba la apariencia ${ }^{11}$, así como es posible que una cierta permisividad se hubiese introducido en los altares domésticos donde se quemaban diferentes hierbas, precisamente, por el similar aroma -igualmente grato a los dioses-que esas desprendían.

La substitución en la ofrenda romana parece operar, pues, con el concepto de la similitud en la apariencia, ya que es de éste del que se hacía derivar la validez de dicha substitución; y son el ahorro, o la protección del patrimonio personal (o, en un caso extremo, la búsqueda de una ganancia) y quizá la escasez de medios económicos los motivos que parecen impulsar estos casos de substitución en la práctica del culto religioso.

7 Colum. I.VIII.5-6 y XI.1.22-23. Vid. también M.H. Jameson, «Sacrifice and animal Husbandry in Classical Greece", C.R. WhITTAKER (ed.), Pastoral Economies in Classical Antiquity, Cambridge $1988,87-119$, esp. 106 y 103.

\& Varro. rust. II.5.11; cfr. Tert. apol. XIV.1. Cfr. PI. Alc. II.149 a, citado por M. H. JAMESON, cit. 87. Vid. mi artículo "La alteridad ritualizada en la ofrenda", Habis (en prensa).

9 Plin. nat. XXIV.102; cfr. Tert. apol. XXX.6 y XLII.7.

10 Svet. lul. LIV.3, Vit. V.2.

$"$ G. BODEI GIGLION, "Pecunia Fanatica. L'incidenza economica dei templi laziali”, RS/ 89, 1977, 49-50, n. 84. En todo caso, Suetonio los presenta como casos sacrílegos: cit. n. 10. A este respecto, es interesante la comparación con testimonios hititas sobre la substitución fraudulenta de victimas sacriticiales por los encargados del culto (G. FURLANI, "Sul testo ittita 'I doveri degli addetti ai templi'», SMSR XIV, 1938, 106-107). 
¿Es posible afirmar que los condicionamientos económicos podían afectar a la naturaleza y a la forma del ofrecimiento personal, en ámbito romano, determinándolo?

El único testimonio que podría proporcionar una respuesta a tal cuestión aparece en el tardío comentario de Servio a la Eneida: "et sciendum in sacris simulata pro veris accipi; unde cum de animalibus quae difficile inveniuntur est sacrificandum, de pane vel cera fiunt et pro veris accipiuntur" $e$ uin sacris, ut supra diximus, quae exhiberi non poterant simulabantur, et erant pro veris» ${ }^{12}$. Es decir, la figuración de aquella víctima que no podia ser ofrecida con materias "moldeables" - pan o cera - garantizaba la validez del ofrecimiento a través de la substitución-simulación del animal real prescrito para un determinado sacrificio.

Las fuentes latinas alababan la diversificada producción de panaderos y pasteleros en relación a las formas que imprimían a esas masas heterogéneas de harina, más o menos dulces, para realizar los liba que, en muchos casos, recibían un nombre según lo que representasen ${ }^{13}$; por ello, el lexicógrafo Festo se interesaba por la etimología del nombre de ciertos pasteles usados en contexto religioso, como las strues, por su especial forma compleja (que representaba, según J. Holland, la calzada de un puente), ofrecidas a Jano, o los summanalia, pasteles con forma de rueda que estarían dedicados (aunque Festo no lo indique) a Summanus ${ }^{14}$. Pero, como es evidente, estos panes o dulces reproducían, simplemente, el símbolo que caracterizaba o representaba a la divinidad a la que eran ofrecidos ${ }^{15}$. Solamente un único testimonio, transmitido también por Festo, podría provocar la sospecha de un posible caso de substitución -en ámbito romano- de animales por pasteles que representaban su figura:

12 Serv. Aen. Il.116.28-30 y IV.512 (ed. Harvard). Este estudio continúa la problemática planteada en mi artículo "El sacrificio de victimas 'modeladas': Servio, ad Aen. II.116", Gerión IX, 1991, 199-244, aplicando el método comparativo según la sugerencia de la profesora G. PICCALUGA de la Universidad "La Sapienza" de Roma (a quien deseo expresar mi reconocimiento y gratitud por sus consejos y estímulo). Este tema constituye el argumento de un libro que estoy preparando.

13 C. A. LOBECK, Aglaophamus sive de theologiae mysticae Graecorum causis. libri tres, Könisberg 1829, 118-119 y 1074-1085; J. ANDRÉ, L'alimentation et la cuisine à Rome, París, 1981 (2ª), 210-215; E. SAglio y M. Besnien, DarSag s.v. "Fictor", 1113 y s.v. "Pistor", 498-499; J. HOLLAND, Janus and the Bridge, Roma, 1961, 272, n. 37; Varro. ling. 5.106, 7.44; Mart. epigr. XIV.CCXXII; Apul. met. X.13.6; Arnob. nat. 7.24; Anth. 190 .

14 "Strues" e "lanua/": Fest.-Paul. 93 L.; J. Holland, cit. (n. 13) 271-274; "Summanalia": Fest.-Paul. 474-475 L.: véase n. 15.

15 R. PEtTAZONI, "La ruota nel simbolismo rituale di alcuni popoli indoeuropei», SMSR 22, 1949-1950, 124-138 y J. Champeaux, "Summanus au solstice d'été", Res Sacrae, Bruselas, 1988, 83-100. J. Holland, cit. (n. 13) passim (casos análogos en Grecia: ibidem 272, n. 37). Vid. más adelante los panes dedicados a Selene, Deméter y Artemis. 
"tauri verbenaeque in commentario sacrorum significat ficta farinacea» 16; pero, dado que esta referencia se halla desprovista de un contexto que permita una interpretación en tal sentido ${ }^{17}$, la prudencia invita a considerar únicamente, por el momento, la utilización en ámbito sagrado de estas representaciones (y quizá no substituciones) de toros modelados con harina. Respecto de la otra materia de modelación citada por Servio, la cera, bastará recordar su conocido uso tanto en la plástica artística profana como en aquella en la que la representación adquiría valores mágico-religiosos de substitución ${ }^{18}$.

Ahora bien, es necesario cuestionar si esta esfera de la representación figurativa, con sus posibilidades teóricas de substitución a través de la apariencia, brindaba efectivamente la posibilidad de una práctica cultual a los menos pudientes que eludiese no sólo los mayores costes de una víctima real sino también las dificultades de su aceptación ritual. A este respecto Servio no se expresa en términos excesivamente claros. La imposibilidad de ofrecer una determinada víctima animal prescrita ritualmente y la dificultad, asimismo, en "encontrarla» para su sacrificio (vid. n. 12) son motivos que podrían ser comprendidos desde un punto de vista económico $y$, aunque el gramático no lo aclare, derivados, entonces, de una supuesta escasez de medios (¿o decisión de ahorro?) de determinados oferentes. Pero la interpretación "económica" del pasaje doble del comentarista restringe el espectro de las variadas y posibles explicaciones de esa imposibilidad o dificultad aplicadas al ofrecimiento de una determinada víctima animal como, por ejemplo, el exotismo o el salvajismo de los posibles animales prescritos para el sacrificio o las peculiaridades y características extrañas o escasas de un tipo de animal, que podrían aducirse también como razones de substitución de la víctima sacrificial. Sin embargo, parece difícil sostener - por cuanto conocemos del sacrificio romano- la existencia de la prescripción ritual de un animal exótico o salvaje, al menos como víctima sacrificial ( $v i d$. n. 114), mientras que respecto de unas características especiales que determinasen su rareza o escasez (por ejemplo, la

16 Fest. $494 \mathrm{~L}$.

17 Se podria atribuir, quizá, a tal testimonio una vinculación con los Ludi Taurii (de los que el propio Festo da alguna noticia: Fest. 479 L.) basándonos en la información de Servio sobre tales juegos: instituidos a causa de una epidemia de peste, "ut lues in has hostias verteretur" (Serv. Aen. II.140). La conjuración de una tal epidemia mediante su transmisión a figuras de toros modelados no seria difícil de defender en el ámbito de la comparación histórico-religiosa: vid. n. 41 y n. 47.

18 E. SAGLIO, DarSag s.v. "Cera", 1019. Verg. ecl. VIII.80-85; Ov. epist. VI.91-92 y am. 111.7.29-30; Hor. sat. 1.8.28-33 y epod. 17.76 y 79 ... Recuérdese la importancia del uso de la masa de pan y de la cera en los Sigillaria o en los ritos de la Dea Dia. 
prescripción de toros blancos para Júpiter ${ }^{19}$ ) pudieron existir casos en los que se tratasen de imitar, mediante subterfugios más o menos caseros, ciertas peculiaridades inexistentes en las víctimas (por ejempo, el toro "blanqueado" con tiza para Júpiter), si bien no existe ningún testimonio de que se recurriese, en tales ocasiones, a una práctica del tipo de la descrita por Servio.

No conviene olvidar, por otra parte, las características de la fuente de información que representa este autor: gramático, comentarista, que usa, copia y combina, sin ejercer una crítica de los testimonios o datos de otros autores, manifestando un espíritu de "anticuario» desde su situación temporal de la tardía antigüedad... No se trata de desacreditar su validez testimonial, sino de situarla en el contexto de sus intereses para definir los límites de su información «histórica» (vid. n. 12) recordando, además, que sólo de otro gramático también (Festo) poseemos algún dato susceptible de ser utilizado, prudentemente, en el sentido de la información serviana. La precisión no es fútil; de hecho, existia toda una tradición lexicográfica que señalaba la pobreza de los oferentes como la causa de ciertos casos de substitución de víctimas animales por sus figuras modeladas en masa de pan o pastel: se trata de la tardía tradición greco-bizantina de los Paroemiógrafos respecto de las prácticas sacrificiales de los -atenienses- pobres ${ }^{20}$; y así, en la Suda, por ejemplo, se conservaba el testimonio de la posibilidad de ofrenda de un buey de pan o pastel, "en lugar de uno vivo", que era más caro ${ }^{21}$. Tal tradición se incluía o, más bien, se utilizaba en la explicación de un proverbio por el que se sabía que a un hombre estúpido se le podía denominar "bous hebdomos", expresión que precisamente designaba a dicha ofrenda-pastel: la estupidez o la falta de sentido se entendían como la pretensión de quien hacía equivaler un buey cocido a uno vivo en el ofrecimiento ${ }^{22}$. Siendo la dicotomía vivo/no vivo la que determinaba la comprensión del proverbio (y la que suscitó la interpretación económica de la ofrenda), la explicación subsiguiente y necesaria del adjetivo "hebdomos" recayó en la elección de aquella tradición por

19 La ofrenda de un "cretatumque bouem" (apud Ivv. X.65 y su escolio) ya fue señalada por J. ToutaIn, DarSag s.v. "Sacrificium", 974-975; G. CAPDEvILLE, "Substitution de victimes dans les sacrifices d'animaux à Rome", MélFr 83, 1971, 299-302, que cita otros testimonios similares. Según VARRón, los sacrificios de toros blancos eran escasos (rust. 11.5.10).

20 P. Stengel, “BOY $\sum$ EB $\triangle O M O \sum »$, Hermes XXXVIII, 1903, 567-574 e id., Opferbräuche der Griechen, Leipzig-Berlín, 1910, 222-233.

21 Suid. S.v. "bous hebdomos" y Macario, Diogeniano, Eustacio y Zenobio citados en P. Stengel, art. cit. y op. cit. (n. 20) con estudio de las variantes.

22 Suid.: "anaisthetos", s.v. "bous hebdomos" y "hebdomaios"; también en Diogeniano, Eustacio y Zenobio: citas y análisis en P. STEngEL, art. cit., esp. 567, n. 1 y op. cit. (n. 20). 
la que se añadía a los seis tipos de animales («vivos»), que eran apropiados para la ofrenda, este "séptimo" (al que recurririan los pobres), constituido por el pastel que representaba la ofrenda de otro tipo de animal, un buey ${ }^{23}$. La interpolación de esta referencia económica respecto del sacrificio animal, señalada por P. Stengel ${ }^{24}$, se producía en un contexto de información sobre pastelería sagrada, transmitida por los lexicógrafos, y en concreto respecto del origen de la denominación de la ofrenda del «bous hebdomos": se añadía un "séptimo" pastel "con cuernos", a imitación de un buey, a las usuales seis "selenai", pasteles redondos y planos, representantes de la imagen de la luna llena, que se ofrecían a Selene ${ }^{25}$; en tal caso, la tradición no conservaba ninguna alusión al modo de hacer de los pobres: se trataba de una prescripción ritual (y no de una substitución de víctimas) por la que se pretendía representar, a través de la forma de este séptimo pastel, el típico y conocido símbolo del creciente lunar ${ }^{26}$. De hecho, los reglamentos de cultos como el de Apolo, Cronos y Hestia prescribían la ofrenda de tales pasteles ${ }^{27}$.

En cualquier caso, una cierta corriente de "interpretación económica" parece haberse creado y fomentado, en un círculo determinado de la transmisión de tradiciones helénicas, respecto de la substitución de víctimas animales en el sacrificio. Tal elección dejaba al margen, excluyéndola, aquella otra "interpretación ética» que se basaba en el rechazo del sacrificio de todo ser con vida (vid. n. 4) y en la institución cultual, en su lugar, de la ofrenda de pasteles sobre los altares; así, por ejemplo, la línea de pensamiento filosófico de Teofrasto, la tradición mítica relativa a las instituciones de Cécrop o las reglas de comportamiento atribuidas a ciertas sectas como las de los pitagóricos u órficos ${ }^{28}$. Cabe recordar, sin embargo, que si bien el gramático Servio incluia la información sobre dichas

23 Suid. s. v. "bous hebdomos" y "thyson": vid. P. STENGEL, art. cit. y op. cit. (n. 20); los tipos de animales eran: oveja, cerdo, cabra, buey/paloma, gallo y ganso (con variación del puesto según las diferentes tradiciones: id. ibidem).

24 P. Stengel, art. cit. 572-573 e id., op. cit. (n. 20) 227-228 y 231-232.

25 Suid. S. v. "bous hebdomos"; también Eustacio, Apostolio y Hesiquio (s. v. "selenas"): P. Stengel, art. cit. 568, n. 1 y op. cit. (n. 20) 223-224. Poll. VI.76; cfr. el pastel denominado "Ampiphon", dedicado a Artemis Muniquia en plenilunio: Ath. XIV.645 a. Véase n. 26.

${ }_{26}$ Suid. s. v. "hebdomaios"; Hor. carm. IV.2.57-58. Pollux indicaba que tal pastel "cornudo" se ofrecía también a Apolo, Artemis y a Hécate (Poll. VI.76).

27 F. Sokolowski, Lois sacrées des cités grecques, París, 1969, 102 y 54, n 52 y n² 25 e id., LSG Supl., Paris, 1962, 56, no 21. P. STEngeL, art. cit. 569 e id., op. cit. (n. 20$) 222$ y 224.

28 Teofrasto apud Porph. Abst. II; sobre Cécrop: Paus. VIII.II.1-3 y I. 26.5. Porph. VP 22; sobre Empédocles: Philostr. VA 1.1. Véase W. BuRKert, op. cit. (n. 4) 26 y C. GrotTANELLI, "Uccidere, donare, mangiare. Problematiche attuali del sacrificio antico", C. GRotTANELLI- N.F. PARISE (ed.), Sacrificio e società nel mondo antico, Roma-Bari 1988, 20-23 
prácticas de substitución en el lema que explicaba un sacrificio humano, el de Ifigenia, su conclusión era la de "virgine caesa non vere, sed ut videbatur" ${ }^{29}$. Evidentemente, Servio no pretendía ser un exponente más de la conocida tradición latina -más o menos tardía- del rechazo del sacrificio cruento sino que el ejemplo legendario, y sobre todo su peculiar conclusión, le servía para demostrar la validez de otras substituciones en las prácticas sacrificiales romanas, basándose en que los «substitutos" parecían y/o simulaban ser verdaderos ( in sacris simulata pro veris accipi»).

Sobre esta teoría de la forma o, más sencillamente, del recurso a la modelación de figuras de animales para la simulación en el sacrificio, el mundo griego ofrece otros testimonios que privilegian la motivación económica; y así, el escoliasta de Tucídides no duda en explicar las "ofrendas (sacrificiales) peculiares o locales" de muchas de las personas reunidas para celebrar el festival ático en honor de Zeus Meiliquio (Diasia) como "pasteles con formas de animales" ${ }^{30}$. Tucídides se refería a una participación masiva de personas $y$, explicando a los lectores no atenienses tales fiestas, distinguia ciertamente entre los que ofrecian victimas sacrificiales y los que, "en su lugar», presentaban aquellas ofrendas peculiares, sin una mayor connotación ${ }^{31}$. Una participación global seguramente suscitaria, dependiendo de los recursos personales, una gran variedad de nivel en las ofrendas ${ }^{32}$. Pero lo que nos interesa destacar es que el comentarista, a través de su explicación, parece hacer equivaler las víctimas normales ("ovejas") y las figuraciones zoomórficas en masa de pan o pastel en el culto de una divinidad cuyas atribuciones, posiblemente, provocaban tal participación generalizada ${ }^{33}$.

Un caso peculiar de la información helénica sobre este tipo de recurso figurativo en el sacrificio lo constituye un testimonio de Heródoto: el historiador griego reconoce como un uso sacrificial entre los pobres de Egipto la modelación de cerdos en pasta, que «cocían y sacrificaban» en vez de

29 Serv. Aen. II.116.27-28 (ed. Harvard). Sobre las tradiciones y la transmisión del tema le. gendario del sacrificio de Ifigenia véase mi artículo, cit. (n. 12) 204-210.

30 Schol. a Th. I.126.6: testimonio estudiado por M. JAMESON, cit. (n. 31 ).

${ }^{31}$ Vid. M. Jameson, "Notes on the Sacrificial Calendar from Erchia", $B C H 89,1965,159-166$.

32 Otros casos en Paus. VII.18.11; D.S. V.4.1-2, IV.23.4, cfr. Paus. III.23.8 y Cic. Verr. II.IV.XLVIII (106-107). La posibilidad encarnada por los upasteles" no excluye la existencia de otro tipo de ofrendas «peculiares": M. JAMESON, cit. (n. 31) 166.

33 Protector de la prosperidad, objeto de culto familiar y vinculado a rituales de purificación...: vid. M. JAMESON, cit. (n. 31) 160-163 y Ch. PICARD, "Sanctuaires, représentations et symbols de Zeus Meilichios", RHR 126, 1943, 97-127. 
cerdos vivos ${ }^{34}$. La "substitución" en el sacrificio se verificaba, entonces, no solo a través de una imitación de la apariencia sino, además, mediante un "tratamiento sacrificial», aspecto significativo sobre el que insistiremos. La ocasión de tales prácticas era el plenilunio y la divinidad a la que se dedicaban era Selene: Heródoto obviaba la explicación del rito del que Plutarco, por el contrario, daría extensa información tanto mítica (sobre la etiología del sacrificio de cerdos en el plenilunio, vinculado a Seth), como ritual, sobre las prácticas que servían para conjurar los poderes maléficos de dicha divinidad: se fabricaban pasteles sacrificiales sobre los que se estampaban las figuras de los animales "tifónicos" atados o encadenados ${ }^{35}$. Es posible, pues, que Heródoto interpretase, según su lógica y sus conocimientos, y confundiese entonces una verdadera práctica ritual (el sacrificio de cerdos modelados) con especiales casos de substitución económica de las víctimas prescritas para determinados sacrificios ${ }^{36}$.

Una interesante dimensión ritual del fenómeno se obtiene con la revisión de la documentación relativa a la figuración zoomórfica en la panadería o pastelería religiosa griega, ya iniciada con los testimonios sobre el buey de «pastel». En este sentido, conviene prestar atención a los ejemplos recogidos por Ateneo: el "elaphos", nombre del pan con forma de ciervo confeccionado para la fiesta ática de las Elaphebolia ${ }^{37}$, reproducía mediante la harina, la miel y el sésamo el símbolo de una divinidad, Artemis, que ya no era sólo la divina protectora de los animales de caza ${ }^{38}$, mientras que los panes de Delos llamados "achainai", también con forma de ciervo ${ }^{39}$ y fabricados para la fiesta de las Megalartia estaban dedicados a una divinidad agraria, Deméter, afligida por la pérdida de la hija, que se

34 Hdt. 11.47.

35 Plu. Moralia 373 C-E (55) y 362 F (30), 371 D (50). Vid. mi artículo, cit. (n. 12) 236-237. Es interesante la comparación histórico-religiosa que establece E. L. R. MEYEROWITZ, The Akan of Ghana. Their Ancient Beliefs, Londres, 1958, 142-144 y 51-81, asi como la que sugerimos con un rito védico que utilizaba panes sacrificiales en la ceremonia de la luna llena: vid. J. GoNDA, "Il sacrificio della luna piena e della luna nuova ed il sacrificio degli animali», Le religioni dell'India. Veda e antico induismo, Storia delle Religioni (ed. Schröder), Milán, 1981, 200-205.

36 Según C.J. BLEEKER, Egyptian Festivals. Enactments of religious Renewal, Londres, 1967, 19 y 31, la referencia de Heródoto no ofrece dudas sobre su autenticidad; véase también A. B. LLoyd, Herodotus. Book II. Commentary 1-98, Leiden, 1976, 219.

37 Ath. XIV.646 e.

38 En los sacrificios dedicados a Artemis la víctima era fundamentalmente la cabra y no el ciervo: M. H. JAMESON, cit. (n. 7) 92 y 100; S. MARINATOS, "Le temple géométrique de Dréros", $B C H$ 60, 1936, 224; W. BURKERT, Mito e rituale in Grecia, Roma-Bari, 1987, 150.

39 Ath. Ill.109 e-f. Forma propuesta por L. BREGLIA PULGI, «Demetra tra Eubea e Beozia e i suoi rapporti con Artemis", Recherches sur les cults grecs et l'Occident II, Nápoles, 1984, 83-85; véase mi artículo, cit. (n. 12) 230, n. 158, y nota siguiente. 
integra en el mundo adulto a través del matrimonio: la referencia a la diosa Artemis, que presidía precisamente estos "pasajes", es ratificada por la presencia de su símbolo animal en aquellos panes ${ }^{40}$. Así pues, se trataba de panes zoomórficos que aun siendo símbolos formalmente de una divinidad, Artemis, del mundo salvaje, de lo no cultivado y marginal, incorporaban -mediante su composición de harina- la precisa referencia cerealística de una actualidad y de una realidad que ya eran esencialmente agricolas (y la presencia de Deméter, en el caso de las Megalartia, lo evidencia con mayor intensidad). Una interpretación similar se podría aplicar también a un rito agrario-pastoral siracusano en honor de Artemis que consistía en el transporte a la ciudad, por parte de los pastores, de panes modelados con formas de animales salvajes ${ }^{41} \ldots$

La posible dimensión ritual de estos panes zoomorfos en el culto de determinadas divinidades prescinde evidentemente de un concepto de substitución de las víctimas que se representaban: la procesión de los panes no poseía, ciertamente, un valor sacrificial y su modelación no constituía, en estos casos, un recurso cultual de los pobres. La valencia agraria de los panes elaborados y su uso ritual, como símbolo de lo cultivado y añadido a una determinada referencia animal, no sorprende; pero para tales representaciones zoomórficas en ámbito clásico, y en un contexto religioso, no solo se usaba la harina sino también - como indicaba Servio - la cera, u otras materias en las que tal valencia es inexistente. Pseudo-Plutarco, por ejemplo, recordaba que había sido acuñada en Alejandría la expresión proverbial "buey locrio" para denominar al pepino que era configurado - mediante unos palillos - como un buey: tal substitución ocurría cuando faltaba este tipo de víctima en un sacrifico público ${ }^{42}$. A la aparente falta de valencia simbólica de esta materia de modelación se une la ausencia de información de la ocasión ritual que requería tal tipo de "substitución de víctimas". Pero, además, se aduce un nuevo motivo (recogido también por

40 Sobre la Deméter del luto y Artemis Eileithyia y su esfera divina común, véase L. BREGLIA Pulcl, cit. (n. 39) 71-88. La traducción de tragos por "Cabra" (apud Ath. Ill.109 e-f, ed. C. BURTON GULICK) podría convenir también a la interpretación ritual referida a estos especiales panes: vid. n. 38 .

41 Se trata del aition siracusano del origen del género bucólico, transmitido por los escolios a Teócrito y seguido por algunos comentaristas de Virgilio (vid. F. Frontisi-Ducroux, "Artémis Bucolique", RHR 198, 1981, 30-56). Es de destacar que las fuentes latinas introducian un contexto de peste en la etiologia del rito, asi como la invocación especial a una Artemis "Lyaea", "que sana" (vid. id. ibidem). La asociación ritual peste/cabra está atestiguada en el ámbito cultual de Artemis (C. Montepaone, "ll mito di fondazione del rituale muniquio in onore di Artemis", Recherches sur les cults grecs et l'Occident I, Nápoles 1979, 66, 68 y 73).

42 Pseudo-Plutarchea XXIV.1257, p. 165 (ed. Deubner). 
Servio), el de la imposibilidad de ofrecimiento de una victima concreta por una falta "ocasional» de disponibilidad de la misma. ¿Se trata, quizá, de otro tipo de interpretación de un uso ritual desconocido, al estilo de aquella proporcionada por los lexicógrafos, si bien éstos se pronunciaban por los aspectos económicos de la substitución?

La sospecha de que tal motivo constituyese la explicación "etiológica» posteriormente atribuida a una costumbre ritual que quizá ya no era comprensible (el testimonio no proporciona datos sobre la divinidad), aparece reforzada por el testimonio similar de un rito atribuido, esta vez, a Hércules Melon. Pollux, la fuente más explícita respecto de la peculiaridad beocia del culto a tal divinidad ${ }^{43}$, consistente en el "sacrificio» de una manzana con palillos - a modo de patas y cuernos-que reproducían la figura de un carnero, partía de la posible polisemia del epíteto local de la divinidad (manzana/carnero) ${ }^{44}$ que resumía el juego de la substitución ritual de la ofrenda. La institución de la costumbre ritual nació, sin embargo y según su propia información, de la solución «infantil» de la modelación de la víctima ante el retraso e imposibilidad de presentación de la misma para el sacrificio durante un festival. Es posible, pues, que existiese un rito -ateniense, según la fuente datable más antigua ${ }^{45}$ - que utilizaba una manzana travestida de animal en este culto local de Hércules; y se podría pensar, tal vez, en un Hércules de la fertilidad ${ }^{46}$ o de la salud y protector frente a las epidemias, según refleja el epíteto ático de Alexikakos con el que aparece asociado ${ }^{47}$.

En todo caso, el subterfugio ritual (etiológico) que consistió en una substitución de la víctima prescrita a causa de su imprevista ausencia sucedió "en un tiempo originario" ${ }^{48}$ : una situación que, evidentemente, no se necesitaba recrear sucesivamente en el culto ya instituido a una determinada

43 Poll. I.1.27 (30-31): cfr. n. 44 y G. CAPDEVILLE, cit. (n. 19) 296-297; A. SchaCHTER, Cults of Boiotia II, Londres, 1986, 21 e id., "The Boiotian Herakles", Act. 2è. Congr. internat. sur la Béotie antique, Montreal, 1979, 37-43; S. WOODFORD, "Cults of Heracles in Attica", Studies Presented to G. M. A. Hanfmann, Mainz, 1971, 218-219.

44 Las fuentes vacilan entre "carnero" y "buey": A. ScHACHTER, op. cit. (n. 43 ) 21 y S. WOODFORD, cit. (n. 43) 218.

45 Apollod. Hist. 244 F 115 (Zen. V.22): A. SCHACHTER, op. cit. (n. 43) 21, n. 4; y concretamente del demos ático de Melite, según Hesiquio (id. ibidem y S. WoODFORD, cit. -n. 43-218).

46 A. SchachteR, art. cit. (n. 43) 37, n. 7, 39; vid. Paus. IX.19.5-6 y 27.8). La asociación ritual carnero/fertilidad está atestiguada en la antigua India: vid. n. 76. .

47 Apollod. Hist. 244 F 115 (Zen. V.22): A. SchACHTER, op. cit. (n. 43) 21 e id., art. cit. (n. 43) 38 y S. WOODFORD, cit. (n. 43) 218-219. Véanse n. 17 y n. 41.

49 Diversamente se concluyó el caso de la "imposibilidad" de los habitantes de Cícico: el subterfugio de la modelación con harina de una ternera para Proserpina no fue considerado "suficiente" ritualmente y por tanto no instituyó ninguna costumbre ritual (vid. Plu. Luc. VII.10.1 y App. Mith. L.XII.75). 
divinidad, pues la ofrenda prescrita era, en el primer caso, la de un pepino con la figura de buey $y$, en este último, la de una manzana con patas y cuernos como si fuera un carnero.

El ámbito religioso helénico muestra, por tanto, una significativa y diversificada casuística de la substitución de víctimas que, aun conociendo los límites de la información que la proporciona, permite discernir entre el motivo económico, el ético, el ritual y el de una indeterminada imposibilidad como origen posible de estas substituciones. Respecto del primero, la interpretación o atribución de una pobreza, de escasos medios y posibilidades económicas, para aquellos oferentes de la antigüedad que recurrieron al sacrificio de animales "simulados" suscita toda una serie de reflexiones sobre su posibilidad ritual. Y la primera de ellas es que tales substituciones se producian acudiendo al extremo inferior en la escala jerárquica sacrificial, en cuanto carente de vida, siendo fabricados, por tanto, substitutos menos costosos y de menor valor y consideración como objeto de sacrificio: ¿es posible que, a pesar de ello, fuesen considerados equivalentes ritualmente a las víctimas mejores y a las adecuadas y, por consiguiente, válidos y permisibles para que el menos pudiente cumpliese con «corrección» con el culto debido?; y, acudir a ello ¿supondría ciertamente la misma confianza en la atención divina y la consciencia de cumplir, de todas formas, con el deber religioso?

La apreciación de Teofrasto (y de sus seguidores) sobre la complacencia de los dioses ante la ofrenda de harina del pobre ${ }^{49}$ sugería simplemente una permisividad, transformada en especulación idealista, de ese posiblemente cotidiano modo de "sacrificar" de los menos pudientes: ese "inquilinus pauper dat molam et libum in ignem", según una fuente latina, que describía precisa y solamente, un uso ${ }^{50}$. Sin embargo, el tipismo sacrificial de los pobres, basado en una reducción considerable del valor de lo ofrecido, aparecía ya codificado en el ámbito semítico bíblico, al menos en el caso prescrito para la expiación de los pecados. Las prescripciones sacrificiales contenidas en el Levítico contemplan la substitución de un animal del rebaño incluso por un décimo de efa de flor de harina, ya que preveían una variación del tipo de "víctima" necesaria para la expiación según el rango de quien lo hiciese ${ }^{51}$. Sin duda alguna, era la

49 Teofrasto apud Porph., Abst. II.17.2, II.15.1...

so Anth. L.VI Ep. 72 (cita de C. A. Lobeck, cit. -n. 13- 1084).

51 Lev. 5.11 y 7 ; véase M. G. AmADAS1-Guzzo, "Sacrifici e banchetti: Bibbia ebraica e iscrizioni puniche", C. Grottanelli-N. F. Parise (ed.), Sacrificio e società nel mondo antico, Roma-Bari, 1988,102 y 100 . 
sentida necesidad e importancia de la extensión del cumplimiento de este tipo de sacrificios a todo el pueblo lo que habría inducido a incluir tal ofrenda vegetal como prescripción sacrificial para los pobres; pero en esa intención de participación parece estar ausente el concepto de substitución de víctimas, asi como también el de una equivalencia de lo ofrecido por las diferentes personas según su patrimonio económico.

Sin tal rigor o control ritual -y debido, quizá, a una espontaneidad privada- se ha podido comprobar también en ámbito helénico que la posibilidad de una participación global, en un rito o festival de dimensión pública, se debía de hacer efectiva mediante la aceptación del uso en los sacrificios de "víctimas menores", de menor coste, de rango sacrificial menor de lo prescrito (vid. n. 32) e, incluso, de la materia "sacrificial" vegetal que adoptaba, sin embargo, la figura de una víctima animal (caso de las Diasia). Pero esta representación no significaba, al menos según la interpretación proporcionada por los lexicógrafos (el escoliasta de Tucídides no se pronuncia en ningún sentido), una equivalencia con la víctima animal real: tal pretensión, como se recordará, era calificada de "sin sentido"; $y$, por otra parte, la "séptima» categoría de víctima atribuida al pastel con forma de buey ${ }^{52}$, derivaba de la interpretación y confusión de tradiciones sobre la explicación de aquel adjetivo ("hebdomos").

Una teorización completa sobre estas cuestiones suscitadas por el hecho de la substitución animal/vegetal en el sacrificio, si bien referida a un ámbito religioso y culturalmente distante, aparece plasmada en los textos rituales védicos ya que su teoría sacrificial basaba la posibilidad misma del sacrificio, precisamente, en su substitución: la mejor víctima era el dios creador, la única que no podia ser utilizada en el sacrificio ${ }^{53}$. Todo sacrificio era, por tanto, la imitación de un ideal, una copia de un prototipo no realizable ${ }^{54} \mathrm{y}$, según la capacidad para representarlo, los teóricos habian confeccionado una inmutable lista jerárquica de las posibles víctimas sacrificiales ${ }^{55}$; de la última, la víctima "menos deseable" (la cabra), se decia, sin embargo, que era la mejor de todas ( $y$, por tanto, la más utilizada) según un relato mítico que explicaba las sucesivas emigraciones y estancias

52 P. STENGEL, art. cit., 570-572 e id., op. cit. (n. 20) 232; vid. n. 23.

5.3 Véase B.K. SMITH-W. DONIGER, "Sacrifice and Substitution: Ritual Mystification and Mythical Demystification", Numen XXXVI, 1989, 189-224, esp. 204 y 198, a quienes seguimos en nuestra exposición sobre el sacrificio védico.

54 B.K. SMITH-W. DONIGER, cit. (n. 53) 216, 197-199.

55 B.K. SMITH-W. DONIGER, cit. (n. 53)199-202 y n. 35 (fuentes: Satapatha Brahmana 6.2.1.13, 18; Aitareya Brahmana 2.8); S. LÉvı, La doctrine du sacrifice dans les Brâhmanas, París, 1966, 133. 
temporales de la "cualidad sacrificial» en cada uno de los tipos de víctima hasta su mayor permanencia - precisamente- en la cabra que concentraba en sí, por tanto, las esencias de las otras víctimas jerárquicamente superiores ${ }^{56}$.

De este modo, la «inaccesibilidad" del sacrificio prototípico introducía e imponía el concepto de una «equivalencia» en el ritual y, por tanto, ofrecía la posibilidad de utilización de aquella víctima de menor categoría, pero más fácilmente asequible, es decir la versión sacrificial menos cara: el concepto de necesidad podía justificar en el vedismo toda substitución sacrificial entre víctimas animales ${ }^{57}$. Los textos rituales aún simplificaban más: el relato mítico informaba que la cualidad sacrificial había pasado, tras la cabra, a la tierra siendo encontrada en el arroz y en la cebada ( $v i d$. n. 56): se instituian así nuevas "víctimas" vegetales, menores, que poseían, sin embargo, tanta potencia como el resto de las víctimas sacrificiales superiores ${ }^{58}$. La posibilidad de esta equivalencia surgía de la búsqueda y atribución de analogías a lo vegetal con las características físicas animales: cuando «un pastel de arroz es ofrecido, lo que se ofrece es, en efecto, un paśu (víctima): su fibroso cascabillo son sus pelos, su cáscara la piel; la harina es la sangre, los pequeños granos la carne, la mejor parte (del grano) es el hueso" ${ }^{59}$. Las ofrendas vegetales podian servir, pues, de substituto de la víctima animal por "necesidades económicas", siempre que funcionasen como si fuesen los originales: la exaltación del substituto como «igual» al original era una estratagema para constituirlo adecuadamente como substituto. A ello se añadía, según indican los textos, un tratamiento ritual-sacrificial idéntico al que se habría aplicado al original; incluso los mantra permanecían inalterables aun cuando existiesen referencias al original ("cabra») ${ }^{60}$ y se estuviese utilizando un substituto (un pastel por la cabra). La verdad ritual consistía en la exactitud en las prácticas y en las fórmulas del sacrificio ${ }^{61}$.

El ritual védico ofrece, pues, un interesante ejemplo de la posibilidad de una práctica real de búsqueda, por parte de cualquier oferente, de lo más

\footnotetext{
56 Aitareya Brahmana 2.89 (y otras fuentes) en B.K. SMITH-W. DoNiger, cit. (n. 53) 201-203 y 221, n. 35; S. LEVVI, cit. (n. 55)136-138.

57 B.K. SMITH-W. DONIGER, cit. (n. 53) 204-208.

58 B.K. SMITH-W. DONIGER, cit. (n. 53) 202-203; vid. n. 59 y Ch. MALAMOUd, "Les chemins du couteau. Remarques sur les découpages dans le sacrifice védique", L'Uomo. Società. Tradizione. Sviluppo IX, 1985, 31-44, sobre el pastel sacrificial.

${ }_{59}$ Aitareya Brahmana 2.8-9 (y otras fuentes) en B.K. SMITH-W. DoNIGER, cit. (n. 53) 203.

60 B.K. SMITH-W. DONIGER, cit. (n. 53) 204 y 208.

61 S. LÉVI, cit. (n. 55) 39.
} 
sencillo, lo menos costoso y lo más común en el sacrificio: un "minimalismo" (hasta el mínimo aceptable) ${ }^{62}$ que nacía de la teorizada necesidad de la substitución en el sacrificio y que se basaba en una equivalencia ritual. Sin embargo, y a diferencia de lo expuesto respecto de otros ámbitos religiosos, esta equivalencia ritual se producía por "concepto", a través de una construcción ideológica y no por percepción; el substituto vegetal (el pastel de arroz) funcionaba "como" si fuera el animal prescrito para el sacrificio, era "tratado" e incluso "denominado" como tal, pero no se representaba ni parece ser necesaria — para indicar dicha «equivalencia"la figuración de la forma del animal al que substituia; por otra parte, la consideración de la «necesidad» en el ritual védico amplía esa esfera más o menos estereotipada de "la práctica de los pobres", referida a la substitución de victimas en el sacrificio, a través del establecimiento de un concepto extenso por el que la práctica de los menos pudientes debia representar, posiblemente, solo un caso más.

El revisionismo practicado posteriormente -tanto por el hinduismo como por el budismo- respecto del sacrificio védico ejercería una crítica sobre bases éticas, conformando una doctrina de la "no violencia" (ahimsā) que implicaba o generaba nuevas substituciones de víctimas sacrificiales. El sacrificio animal era rechazado a través de una estrategia racional de "lo nuevo": conservando la apariencia y/o la referencia a la vieja categoría sacrificial védica (que aportaba una legitimidad), se señalaba la "mejoría" y la mayor verdad de los nuevos sacrificios no sangrientos ${ }^{63}$. Surgen las divinidades "vegetarianas" hindúes $y$, así, las ofrendas de arroz y cebada serán consideradas mejores que las de los animales, si bien no eran víctimas animales ${ }^{64}$ sino símbolos de aquellos sacrificios cruentos del pasado védico que se habían convertido en objetables ${ }^{65}$.

Es de señalar que este comportamiento religioso de distinción -respecto de su origen doctrinal- y de crítica, basada en una ética evolucionista que rechazaba lo cruento, era el que generaba las prácticas de substitución sacrificial del animal por lo vegetal y sin vida, tal y como se indicó al referirnos a ciertas corrientes filosóficas y a ciertos círculos de interpretación

62 B.K. SMITH-W. DONIGER, cit. (n. 53) 205-206.

63 B.K. SMITH-W. DONIGER, cit. (n. 53) 215.

64 B.K. SMITH-W. DONIGER, cit. (n. 53) 208.

65 B.K. SMITH-W. DONIGER, cit. (n. 53) 214; se acudia, en muchos casos, a la modelación de las formas animales: vid. A. M. ESNOUL, "L'induismo" y A.M. BLONDEAu, "Le religioni del Tibet", H. C. PueCH (ed.), Le religioni dell'Estremo Oriente I, Roma-Bari, 1988, 97 y 320. 
mítica y/o ritual del mundo grecorromano. Pero, como fenómeno "evolucionista", parece estar atestiguado en el desarrollo de todas las religiones superiores. También en el judaísmo, los defensores de una religión pura yahvista denunciaban la desviación del culto sacrificial con víctimas animales por su similitud con ciertos actos paganos; $y$, asi, los profetas lanzaban invectivas antisacrificiales propugnando una atención mayor al espíritu de sacrificio que a las prescripciones rituales sobre las que, por el contrario, insistía la Ley ${ }^{66}$. A esta corriente de espiritualización del sacrificio en el mundo bíblico pertenecía la proclamación del incienso como sacrificio ideal, como la ofrenda racional y no cruenta ${ }^{67}$. Pero el ejemplo más claro lo proporciona la comunidad de Qumrán, exponente de un alejamiento y crítica del sacerdocio de Jerusalén, considerado ilegal aun cuando no se hubiera rechazado el templo de la ciudad y sus ritos sacrificiales; en la espera del advenimiento de un sacerdocio legítimo, el sacrificio adquirió en ella una perspectiva escatológica $y$, mientras tanto, sería espiritualizado reconociéndose la «equivalencia de la oración de alabanza como sacrificio agradable a Dios» ${ }^{68}$.

El criterio ético, pues, como motivo de prácticas de substitución en el sacrificio que provocaba la búsqueda de una forma no cruenta, aparece adoptado por corrientes evolutivas de interpretación en momentos determinados, quizá cruciales, del desarrollo de las religiones superiores; pero su adopción en comunidades o sectas pudo haber sido provocada por un efectivo horror ante lo sangriento que, además, les serviría para disgregarse de su entorno religioso y para "exhibir" un comportamiento cultual/ritual diverso de la norma. En tales prácticas, que pretendían obviar el sacrificio de la vida animal, su referencia no podía existir: la figuración plástica del animal-víctima consistiría, probablemente, en un mero símbolo añadido a lo vegetal pues lo que se "sacrificaba" no poseía vida. La actitud ética, por tanto, no era la que provocaba la necesidad de una equivalencia ritual entre la víctima real animal y su substituto vegetal a través de la imitación de su figura.

Se hace necesario, en este punto de nuestro estudio, ampliar la investigación con la documentación etnográfica relativa a tales prácticas sacrificiales, ya que estas forman parte también de la vida ritual de las sociedades tradicionales a causa, fundamentalmente, de una falta de disponibilidad

66 L. Sabourin, Dictionnaire de la Bible, Supl. X, s.v. "Sacrifice”, París, 1985, 1493-1494 (cita fuentes). La intención, pues, se valoraba por encima de lo ofrecido: cfr. p. 1.

67 Según el Testamento de Levi: cita y comentario en L. SABOURIN, cit. (n. 66) 1504.

68 L. SABOURIN, cit. (n. 66) 1505-1506; vid. también n. 101. 
de la víctima para el sacrificio, de la escasez de medios del oferente y/o por ahorro.

Entre los grupos árticos del NE de Siberia, los Koriak y los Chukchi ${ }^{69}$, el sacrificio por excelencia es el del reno, ofrecido al Ser Supremo y a los espíritus maléficos. Sometidos a un régimen de vida nómada, y sus rebaños a la influencia nefasta de diversos avatares, podian existir ocasiones en las que fuese dificil disponer de un animal del rebaño para un determinado sacrificio, lo que daba lugar a una práctica de substitución aceptada: en vez de un reno, se podía sacrificar uno modelado en madera o con nieve ${ }^{70}$. El poder atribuido por estos pueblos a la representación figurativa para invocar o incorporar una realidad es evidente ${ }^{71}$ y contaba, además, con un prototipo mítico ${ }^{72}$; pero es interesante señalar que la nieve o la grasa ( vid. $\mathrm{n}$. 70 ) son materias de modelación con las que se podía imitar con verismo el color ritual de la víctima que era particularmente grato al Ser Supremo ${ }^{73}$.

Una equivalencia ritual similar se halla también entre los Saoras de India. Su víctima sacrificial por excelencia es el costoso búfalo, necesario para las ocasiones importantes ${ }^{74}$, si bien victimas menores (como cabras, $e$ incluso peces o cangrejos) pueden ser utilizados en los sacrificios menores ${ }^{75}$. Pero, en el área Sogeda, el fruto oval del Artocarpus integrifolia se usa en ocasiones como substituto de la cabra: en tal caso, unos trozos

69 I. PAULSON, “Le religioni dei popoli artici", H. C. PUECH (ed.), Le religioni dei popoli senza scrittura, Roma-Bari, 1987, 351-357.

$7_{0}$ W. Jochelson, The Koriak. Religion and Myths, Leiden-Nueva York, 1905, 92-96, 25; M. A. Czaplicka, Aboriginal Siberia. A Study in Social Anthropology, Oxford, 1914, 291 y 294 (también figuras de renos hechas con hojas de sauce); E. LOT-FALCK, Les rites de chasse chez les peuples siberiens, Mayenne, 1953, 73-79, 88-89, 101 ss.; V.V. ANTropova, "The Koryaks" e id.V. G. KuZnetsova, "The Chukchi" (figuras de renos hechas con grasa o raices), M.G. LEVIN-L.P. Potapov (ed.), The Peoples of Siberia, Chicago-Londres, 1964, 854-855 y 799, 822.

7 W. Jochelson, cit. (n. 70) 96. Ciertamente, el uso de la figuración zoomórfica entre estos pueblos es amplio y de carácter y valor mágico-sagrados (por ejemplo, en el festival de la ballena o en el del oso, o con ocasión del inicio de la estación de caza): véanse id. ibídem 72 y 88 y E. Lot-FALCK, cit. (n. 70) 88-89, $101 \mathrm{ss,} \mathrm{119-126.}$

72 En el tiempo mítico, el "Gran Cuervo" - enviado por el Ser Supremo para organizar el mundo- había modelado unos renos en madera que adquirieron, posteriormente, vida (W. JOCHELSON, cit. - n.70- 22, 232).

73 W. JOCHELSON, cit. (n. 70) 92. Existen indicios, además, de que en un tiempo los vasos sacrificiales se fabricaban con nieve (V.V. ANTROPOVA-V.G. KuZNETSOVA, cit. (n. 70) 822).

${ }_{74}$ V. ELWIN, The Religion of an Indian Tribe, Oxford, 1955, 189-190, 192 y 445, que señala el endeudamiento de los Saoras por las peculiares condiciones de la adquisición de los búfalos impuestas por la tribu vecina, los Dom. Las ocasiones que requieren este tipo de sacrificio son la muerte, una grave enfermedad o la erección de menhires para alojar a fos espíritus (ibidem 189 , 360).

V. Elwin, cit. (n. 74) 188 y 193. Véase también el caso del rito Guarsal (n. 80). 
pequeños de madera se le insertan para simular las patas y los cuernos del animal. Es posible que tal substitución se produzca por motivos económicos, dado el endeudamiento de este pueblo por causas religiosas (vid. n. 74) pero, en todo caso, interesa añadir que se trata de un fruto popular, ampliamente consumido, y que es tabú talar el árbol de tal fruto ${ }^{76}$ : la valencia y relativo valor de la «materia de modelación» no es del todo suprimible, por tanto, en el concepto de las substituciones que pretenden 0 buscan un menor coste de la víctima sacrificial $y$, en consecuencia, un efectivo ahorro. $Y$, así, la utilización de una manzana travestida de carnero, en modo semejante al relatado, en el culto de Hércules Melon (en ámbito religioso griego), podría explicarse, quizá, si este fruto era efectivamente valorado como símbolo de fertilidad, de vitalidad y lozania, según sugería - por otra parte-Pausanias (vid. n. 46).

Los melanesios del SE de las islas Salomón pueden utilizar víctimas menores y menos costosas en substitución del cerdo, que protagoniza por excelencia el sacrificio de combustión para los espiritus; puesto que este se reservaba para las ceremonias importantes, en algunas fiestas de difuntos el zorro volante y los huevos de megapodio podían substituirlo en el sacrificio y posterior banquete. El valor ritual de tales substitutos está atestiguado: los dientes del zorro volante son ofrenda típica de los espíritus del Mar y los huevos de megapodio, pájaro de mal agüero, poseen ciertamente un uso sacrificial ${ }^{77}$. Pero cuando estas víctimas se usan en substitución del cerdo son denominadas, precisamente, "cerdo", ya que substituyen al sacrificio por excelencia. La aceptación de esta substitución o - lo que es igual- su validez reside en una equivalencia conceptual: se mantiene el nombre de la victima, lo que supone la conservación de la valencia ritual del cerdo a pesar del cambio de apariencia ${ }^{78}$, y se mantiene el tipo de tratamiento sacrificial, la combustión, que remite, por tanto, al sacrificio prototipo del cerdo. Junto a la necesidad o a la posibilidad de ahorro de los básicos animales de cría de este pueblo (que constituyen su riqueza), este ejemplo ilustra además la posible y no despreciable valoración social y ritual de los «substitutos» de menor valor económico.

76 V. ELWIN, cit. (n. 74) 205. Las figuras de un carnero y de una oveja, fabricadas con harina de cebada y revestidas con lana eran usadas en el sacrificio védico a Varuna, como dios de la cebada, para la obtención de lluvia, fecundidad y crecimiento vegetal (J. GoNDA, cit. -n. 35- 125, 202).

77 W.G. IVENS, Melanesians of the South-east Solomon /slands, Londres, 1927, 37, 241, 250 y esp. 251, 179, 202, 205, 407 y 220 .

78 Cualquier otro substituto podrá ser llamado "cerdo" y ser quemado (W. G. IVENS, cit. - $n$. $77-241)$. 
Un caso similar de substitución entre víctimas de diferente valor económico lo hallamos entre los Saoras de India. Para el rito denominado Guarsal se requiere el sacrificio de un búfalo ${ }^{79}$; pero, dado que la ceremonia sería excesivamente costosa, el búfalo puede ser substituido por un pez, que es llamado "búfalo" y es tratado sacrificialmente como si lo fuera: «arrastrado hasta el árbol, impelido con un bastón, y presentado al espiritu como búfalo, una vez que el pez se situó ante el altar, con un hacha fue cortado por la mitad, un trozo del mismo se ató a un palo y fue transportado por dos hombres sobre sus hombros» ${ }^{80}$. La actualización ritual de ese inmutable concepto sacrificial eliminaba la necesidad de una equivalencia a través de la percepción visual entre la víctima prescrita y su substituto. Sin embargo, ha de tenerse en cuenta que, aunque el ahorro es evidente, este no implica la ausencia de una especial elección de la víctima-substituto basada en su valor simbólico, específico y adecuado al rito en el que es utilizado: el pez, vinculado a la corriente de las aguas, se usa precisamente en todas las ceremonias relacionadas con la circulación de la savia en las palmeras ${ }^{81}$.

Para el estudio de estas prácticas de substitución de tipo "conceptual» existen otros testimonios (en los que el substituto es buscado en el reino vegetal) proporcionados por ciertos pueblos nilóticos del Sudán que han sido especialmente clasificados por los etnólogos como casos de substitución económica ${ }^{82}$. El sacrificio por excelencia entre los Nuer, pueblo ganadero, es el de un buey. Ahora bien, la estrecha dependencia socio-económica respecto de sus rebaños, su clara identificación con estos animales ante la entidad sobrehumana (hombre=buey; recepción en la iniciación de nombres derivados del ganado) ${ }^{83}$ y la atribución al ganado de una importante cualidad sobrenatural y, por tanto, de un valor ritual y social ${ }^{84}$ determinan que la víctima sacrificial sea denominada siempre yang,

79 Véase n. 74; sobre la ceremonia Guarsal, realizada cuando el espiritu de un difunto interrumpe la circulación de la savia en una palmera, véase V. ELwIN, cit. (n. 74) 193 y 308-310.

80 Descripción de V. ELWIN relativa a la ceremonia Guarsal del 16 de diciembre de 1950 en Boramsingi (id., cit. - n. 74-308-310).

Bi V. ElWIN, cit. (n. 74) 307. Vid. n. 79

82 A. Catemaro, Linee di Antropologia Culturale II, Nápoles 1978, 111 y n. 52 y E. LeACH, Culfura e comunicazione. La Jogica della connessione simbolica, Milán, 1981 (1976), 113-114: ambos se refieren al caso de la substitución de un buey por un pepino entre los Nuer utilizando los datos de E.E. Evans-PRITChaAd (E. LEACH se basa en los primeros escritos de este autor y, por ello, se refiere a la substitución por una «sandia»).

83 E.E. Evans-PRITCHARO, "Some Features and Forms of Nuer Sacrifices", Africa XXI, 1951.2, 112.121 e id., Nuer Religion, Oxford 1956, passim.

${ }_{84}$ Véanse las importantes precisiones a los estudios de E.E. Evans-PRITChard sobre los Nuer realizadas por $P$. BONTE, "Le bétail produit les hommes. Sacrifice, valeur et fétichisme du bétail en 
literalmente "vaca" (vaca ancestral-mítica del rebaño, identificado con el clan) y en sentido genérico "sacrificio bovino" ${ }^{85}$. La falta de disponibilidad o de posibilidad económica para la realización del sacrificio de un buey, o el deseo de la protección del rebaño mediante su ahorro, provoca la utilización de otras víctimas menores como ovejas o carneros, pero además se podía recurrir a un pepino, $\mathrm{kwol}^{86}$, denominado ritualmente "kwol yang" y tratado sacrificialmente como si fuera un buey. $E$. E. Evans-Pritchard insiste en que para los Nuer no se produce una identificación entre ambas víctimas sino una equivalencia basada en el concepto del sacrificio ( $y$ no en la percepción de características similares) y, en consecuencia, en la similitud de la práctica ritual sacrificial ${ }^{87}$. Tal substitución se produce también en el caso de un sacrificio temporal (que precede al requerido de mayor valor y diferido por dificultades económicas), de un mal sueño o de un incesto de poca importancia, es decir para ocasiones de valor o importancia ritual menores ${ }^{88}$. Pero, en cualquiera de estos casos, el pepino es presentado, consagrado e invocado ante la entidad sobrehumana como si fuera un buey e inmolado a semejanza de tal víctima; así, si en el caso de grave incesto es un buey el que debe ser abatido y sajado desde la cabeza hasta el rabo, en uno de menor importancia es un pepino el que se corta longitudinalmente, la mitad izquierda es lanzada, la derecha se exprime y su jugo lo beben los participantes ${ }^{89}$. El pepino, pues, aun siendo considerado como una "victima" menor, es aceptado como "suficiente» ritualmente, y no sólo para ocasiones también de menor importancia. Al igual que entre los melanesios y los Saoras, existe un "mínimo aceptable" -establecido por este pueblo- en la jerarquía de víctimas sacrificiales, pero en esa posibilidad de aceptación indudablemente influía la percepción simbólica que del pepino podia existir para su especial uso ritual. El estudio de R. Norrman sobre los aspectos metafóricos atribuidos universalmente a las

\footnotetext{
Afrique de l'Est", L'Uomo. Società. Tradizione.Sviluppo IX, 1985, 123-124, 131-132, 134-135, 138 y $142-143$.

85 E.E. Evans-Pritchard, op. cit. (n. 83) 202-203, 248-266...

${ }^{86}$ E.E. Evans-Pritcharo, op. cit. (n. 83) 202-203, n. 1: se trata del Cucumis prophetarum que crece salvaje en lugares cultivados. Véase también $n$. 91.

87 E.E. Evans-Pritchard, op. cit. (n. 83) $128,133-134$ y 142. Véase también A. Hayler, "Simbolic Equations: the Ox and the Cucumber", Man III, 1968.2, 262-271 y P. BONTE, cit. (n. 84) 143.

${ }_{88}$ E.E. Evans-Paitchard, op. cit. (n. 83) 184, 203, 205, 298 y passim. Véase n. 89.

89 E.E. Evans-PritchARd, op. cit. (n. 83) 203-204, 211-212, 216, 184 ...(Ciertamente importa el lado hacia el que se inclina el buey una vez sacrificado: el bueno es el derecho). Con ocasión de una muerte, y ante las dificultades económicas de la familia del difunto, se puede recurrir también al "corte sacrificial" de un pepino (ibidem 146).
} 
cucurbitáceas ${ }^{90}$ demuestra la adecuación y propiedad metafórica "pepino/buey" vigente entre los Nuer a través de la correspondencia entre la intrínseca y simbólica percepción "universal» del pepino como fuente de riqueza y de vida y una idéntica concepción del ganado en este pueblo ${ }^{91}$. A ello se añade además, para la ocasión de su uso en el incesto, las referencias formales sexuales atribuidas — también universalmente- al pepino, junto a su contenido acuoso considerado como "purificador» ${ }^{92} .$.

El valor sagrado del pepino es reconocido también por un pueblo vecino de los Nuer, los Dinka, ya que lo utilizan para protegerse o curarse de enfermedades o para atraer la pesca, precisamente por una percepción visual del poder sobrehumano en tal fruto ${ }^{93}$. Las víctimas menores como ovejas y cabras pueden substituir también al ganado bovino en el sacrificio y "representarlo" (fundamentalmente en casos de "crisis menor»); incluso el pepino puede ser usado de este modo cuando no se dispone de la victima animal pero, a diferencia de los Nuer, es considerado solamente como substituto temporal (sacrificado mediante división) hasta que se pueda realizar un sacrificio animal ${ }^{94}$. Es interesante informar de que en la proximidad de ambos pueblos habitan los Mandari, que utilizan pepinos también en ciertas ocasiones rituales. Pero entre ellos la equivalencia es mucho menor entre el hombre y el ganado ${ }^{95}$ : el sacrificio de animales productivos se confina a situaciones especiales y las prescripciones rituales parecen contemplar la restricción de sus rebaños, existiendo toda una gama de posibles equivalencias entre víctimas $y$, por tanto, de substituciones de clara raíz económica, si bien respetan un principio basado en las "cualidades de temperatura" de cada víctima ${ }^{96}$. Pero en el rito mensual de "eliminación" (ante la permanente posibilidad de haber cometido algún pecado) se usa un pepino, denominado con la palabra dinka koljok, que se corta en dos y es llamado "vaca»; a su valor para expiar se une, además,

\footnotetext{
90 R. NorRman, “A Note on the Cucumber-Sacrifice among the Nuer», Temenos XVI, 1980, 103-121.

91 Del pepino se percibe visualmente su riqueza en agua, su crecimiento veloz, su gran número de semillas... vid. R. NORRMAN, cit. (n. 90). Debe considerarse también la posible asociación metonímica entre el ganado y este fruto ya que el pepino crece en el estiércol de los recintos para los bueyes (prof. KaRP cit.: id. ibidem 120, n. 67)

92 R. NORRMAN, cit. (n. 90) 114-117.

93 G. LIENHARDT, Divinity and Experience. The Religion of the Dinka, Oxford, 1961, 208-209, 225, 257 (su color verde-azulado sugiere a los Dinka el cielo tormentoso y, por tanto, la presencia de la divinidad) y 278.

94 G. LIENHARDT, cit. (n. 93) $24-25$ y 257.

95 J. Buxton, Religion and Healing in Mandari, Oxford 1973, 9.

96 J. BUXTON, cit. (n. 95) 9-11 y 398-399.
} 
una valencia profética sobre la salud a través de la posición que adopten las mitades del pepino al caer (vid. n. 86). No obstante, tal ritual no comporta un verdadero sacrificio, ni una substitución de víctimas como entre los Nuer, a pesar de la aplicación similar de una división y de una denominación zoológica al pepino utilizado. Indudablemente, una serie de influencias y de préstamos se han producido a nivel lingüístico y en cuanto a los gestos, a los que se suma una cierta facilidad del pepino para resolver las exigencias de un ritual que era propio y local (barato, almacenable $y$, sobre todo, fácilmente divisible en dos partes iguales) ${ }^{97}$.

La necesidad de una prudencia en el análisis de testimonios que parecen similares queda ilustrada, pues, incluso dentro del reducido ámbito de los pueblos nilóticos, pero también la evidencia de las percepciones simbólicas locales de un elemento ritual común que, aun pudiendo variar de valencia, ejemplifican su indiscutible valor general ritual. No será, pues, imprudente recordar el caso del pepino que entre los antiguos locrios (vid. n. 42) substituía a un buey imitando su figura, aun cuando la percepción de las "peculiaridades" del substituto deban restringirse, por ejemplo, al testimonio de Ateneo: en época antigua, los etimólogos consideraban que los nombres de las cucurbitáceas revelaban vitalidad y fertilidad existiendo, en este sentido, un uso proverbial de estos frutos en la antigua Grecia ${ }^{98}$. El sacrificio de este pepino pudo ser considerado, pues, como el equivalente al de la vida de un buey.

Los datos etnográficos presentados configuran una noción «ritualizada" del ahorro (o de la incapacidad económica para afrontar el valor de un sacrificio prescrito), plasmada en la práctica de una substitución sacrificial a través de una simulación de la víctima. Se acude, pues, a un conjunto ritual de formas, gestos, fórmulas y símbolos que hacen posible la aceptación del substituto aun cuando este represente un valor mínimo, ya que se trata de un mínimo "ritualizado" y, en cierta medida, prescrito o al menos sugerido por su suficiencia en la eficacia del ofrecimiento privado (una situación que recuerda, evidentemente, el «minimalismo» védico).

Finalmente, ante sacrificos generales en los que existe una obligación de participación se produce, en ámbito etnográfico, un tipo de respuesta simplificada por parte de los sectores menos pudientes, ya que restringen el sacrificio prescrito al ofrecimiento de aquella libación $u$ ofrenda vegetal que usualmente lo acompaña, o a la elección de una víctima de menor

J. Buxton, cit. (n. 95) 237-243.

Ath.ll.58 f-60 b; Ill.73 d-74 c (vid. R. NorRman, cit. -n. 90-110). 
coste. Por ejemplo, para la celebración del gran sacrificio por los difuntos, los Bambara (agricultores del río Níger) deberían utilizar una gallina blanca si bien, en su defecto, pueden ofrecer simplemente la típica libación de agua y harina de mijo y la nuez blanca (kola) ${ }^{99}$, mientras que el festival de primavera de una tribu mongólica, criadora de ganado, fue celebrado en cierta ocasión con el sacrificio de víctimas diversas según las posibilidades económicas de los oferentes: los ricos, caballos, los menos pudientes ovejas y cabras ${ }^{100} \ldots$

La necesidad, pues, de recurrir a una simulación de la víctima procede, fundamentalmente, de un contexto privado de obligación o de deseo de sacrificar a la entidad sobrehumana y no de un contexto general sacrificial en el que la participación conjunta se podía beneficiar no sólo de aquellos sacrificios realizados en el modo y con el valor prescritos, sino también del previo establecimiento de una serie de variadas posibilidades de ofrecimiento que contempla tanto la posibilidad de eludir el sacrificio animal por motivos económicos como la de la adquirir una víctima de menor valor.

Tras esta información, el fenómeno de la substitución de una víctima, a través de la simulación de lo real, adquiere su justa situación en la escala de los ofrecimientos privados: cuando el sacrificio ha de ser cruento, ha de implicar la anulación de la vida animal se requiere una referencia "vital» en aquello vegetal o inerte que substituye a la víctima, un símbolo de vida que se percibía bien a través de la simulación de la forma del animal, bien a través de la denominación y del tratamiento sacrificial del substituto como si fuera la víctima viva real.

Es de sobras conocida la valencia creativa de la palabra, su capacidad para recrear y representar una realidad a través de su enunciación; el nombre crea la realidad que denomina y precisamente en tal posibilidad radica su utilización en las prácticas de substitución en el sacrificio, según manifiestan los ejemplos aducidos (en el vedismo, entre los melanesios, los Nuer o los Saoras). Pero no solo servía para poder substituir ritualmente a las diferentes victimas (de forma univoca): se denomina "cabra" a un pastel, "cerdo" a un zorro, "buey" a un pepino, "búfalo" a un pez, sino también en cuanto adecuado substituto lingüistico/conceptual de la víctima real "denominada» ("cabra» por una auténtica cabra). Esta fue la solución adoptada por el pueblo judío cuando, tras la destrucción del templo de

99 J. HENRY, L'ame d'un peuple africain. Les Bambara, Münster 1910, 233 y n. 4, 32.

100 Testimonio de T.W. ATKInson sobre los Calmucos, citado por M.A. CZAPLickA, cit. (n. 70) 304 y n. 3. 
Jerusalén, quedó anulado todo servicio divino siendo imposible, por tanto, la práctica del sacrificio; este se consideró temporalmente suspendido y se buscó un modo de perpetuarlo sin sacerdotes y sin templo mediante su espiritualización; y, así, los profetas proclamarán la equivalencia de la oración, el "sacrificio de los labios", con el antiguo sacrificio de la víctima animal: las oraciones tendrían lugar en los momentos del día en los que se acostumbraba a ofrecer sacrificios en el templo y consistirían en la recitación de aquellos pasajes de la Ley referidos al sacrificio. La imposibilidad material de realizar los antiguos sacrificios determinó, pues, la necesidad de su substitución mediante la palabra, y la evolución hacia una espiritualización -ya presente en el ámbito bíblico- garantizó la posibilidad de su equivalencia con las antiguas prácticas prescritas ${ }^{101}$. También en el hinduismo, la "mera recitación del Veda, se comprendiera o no su significado, se consideraba como un equivalente simplificado de la realización de un sacrificio védico" 102; en este caso se trataba del peculiar "concepto de imposibilidad" de ese ritualismo considerado como un original inaccesible (el del vedismo).

A la asignación y pronunciación del nombre de la víctima substituida sigue indisolublemente, según muestran ciertos ejemplos de substitución presentados, la simulación del tratamiento sacrificial prescrito según los diferentes usos rituales. $Y$ el gesto que condensa y materializa el acto del sacrificio en esas substituciones de víctimas animales es el de "cortar»: la acción de la "división» aplicada a los substitutos equivale, como acción ritual, a la muerte sacrificial de una víctima real. A los casos citados y proporcionados por las prácticas rituales de las sociedades tradicionales (entre los Nuer, los Saoras...) ${ }^{103}$, se pueden añadir las contenidas en los rituales védicos ( vid. n. 60) e, incluso, en algunos ritos hititas en los que se evidencia que "romper o despedazar" el pan era considerado un acto sacrificial y equivalente al tratamiento de la víctima animal en el sacrificio ${ }^{104}$.

101 "Sacrificio de los labios": Ho.14.2 y otras fuentes (vid. J. Hastings, ed. Encyclopaedia of Religion and Ethics XI, Edimburgo 1920, s.v. "Sacrifice", 25-26 y L. SABOuRIN, cit. -n. 66-15061507 y 1512). Vid. n. 66 y n. 67.

102 B.K. SMITH-W. DONIGER, cit. (n. 53) 208 y n. 43.

103 Es significativo el caso del sacrificio de cualquier animal en uel huevo" practicado por los Gurmantché, mediante el corte de la cáscara de un huevo de gallina y la expansión de su substancia: tal acto se entiende como la destrucción de la vida al ser paralizada, de este modo, la reproducción de una línea animal (la que se elige e invoca para la ocasión determinada): M. CARTRY, "Le suaire du chef", id. (ed.), Sous le masque de l'animal: Essai sur le sacrifice en Afrique Noire, París, 1987, 164-165, 174 y 224.

104 J. B. Pritchard, Ancient Near Eastern Texts Relating to the Old Testament, Princeton 1950, 348-349 y 360-361 (KUB XXVII, 67; VII.5+ VII.8+ IX.27 y Kbo IV.9); W. BURKERT, cit. (n. 4) 50 y n. 164 e id., cit. (n. 38) 91 y n. 128. Véase también G. Furlani, cit. (n. 11) 94. 
En este sentido, cómo no recordar la ya antigua interpretación sacrificial de la "Última Cena" a través del "troceo" del pan, equivalente y en «substitución» del sacrifio cruento del cordero pascual ${ }^{105}$... La asociación denominación-tratamiento sacrificial de la víctima substituto (que comportaba su división-distribución mediante cortes con cuchillo) aparece de este modo claramente atestiguada en el mundo indoeuropeo.

La metáfora del ofrecimiento de la palabra, o de la poesía, como víctima sacrificial existía efectivamente en ámbito griego; de Píndaro se decía que, en alguna ocasión, tuvo la intención de sacrificar un "peán" a Apolo y de inmolar un "ditirambo" a Dioniso, se entiende, en substitución de una oveja y de un toro respectivamente según imponía el uso habitual ${ }^{106}$. La equivalencia entre las "víctimas" no solo era de tipo económico (la poesía poseía un estipulado valor en carne; el premio en un concurso de ditirambos era un toro) sino que se basaba, fundamentalmente, en una analogía de gestos y conceptual respecto de un tratamiento análogo de "división", de "corte" del discurso, paralelo al aplicado a las víctimas sacrificiales. De hecho, los primeros teóricos de la métrica y de la poética usaron como paradigma de tales disciplinas la práctica de la carnicería sacrificial; en el s. V aparece la figura del logomageiros, el carnicero sacrificial que "corta" el logos; las palabras son definidas como "bovinas" por Eurípides ${ }^{107} \ldots$ Y también en los brahmana hindúes se encuentra un principio de homologia entre verso y ser vivo que determina la consideración del metro poético como víctima sacrificial (cuatro versos=cuadrúpedo, animal sacrificial por excelencia) ${ }^{108}$... La posibilidad y necesidad de la división del discurso (su organización mediante pausas, cesuras...) generaba, pues, la referencia simbólica, e incluso metafórica, al sacrificio animal del que se retenía la importancia del desmembramiento y distribución de su carne ${ }^{109}$.

De este modo, emerge con evidencia la importancia del uso, en las prácticas de substitución a las que nos hemos referido, de un substitutovíctima cuya "materia" sea susceptible de un tratamiento de división y distribución, al menos siempre que se produzca la asociación metafórica de tal materia con la carne de una víctima sacrificial real (caso de los

tos Vid. W. BuRkert, cit. (n. 104) y L. SABOURIN, cit. (n. 66) 1515 ss., 1536.

106 Schol. a Pi. 1.3.18-19 y Phld., Mus. 4, col. 21, 6-13: citados y analizados por J. SvenBRO, «ll taglio della poesia. Note sulle origini sacrificali della poetica greca", C. GRotTANELLI-N.F. PARISE (ed.), Sacrificio e società nel mondo antico, Roma-Bari, 1988, 231-234, n. 1 y n. 41.

107 Informaciones de J. SvenBRO, cit. (n. 106) 231-252 (con citas de fuentes).

108 C. Grottanelli, cit. (n. 28) 33-34 y n. 115.

109 Sobre el sacrificio animal, véase C. GRotTanelLI-N.F. PARISE (ed.), cit. (n. 106). 
pasteles védicos, del pepino de los Nuer, del pez de los Saoras, de los panes-víctima hititas, de la hostia cristiana, del discurso poético...).

Respecto del otro «modelo» de substitución, precisamente el atestiguado por Servio, consistente en la simulación de la forma de la víctima animal que recreaba la realidad substituida, se puede afirmar que ha sido y es practicado universalmente por su eficacia mágico-religiosa y cultural. En su momento se señaló la importancia de la valencia o del simbolismo especialmente atribuido a la materia de modelación escogida (la referencia agraria en los panes zoomorfos, la valencia vital de ciertos frutos como el pepino o la manzana, quizá la valencia sagrada de la nieve entre los pueblos árticos), así como se sugirió la aparente necesidad de unas características físicas de la misma que permitiesen la aplicación de un tratamiento sacrificial "auténtico" (la división, la combustión...). Sin embargo, parece evidente la inexistencia - según los testimonios estudiados- de un binomio conceptual que aúne «figura» y "tratamiento sacrificial» en estas prácticas figurativas «sacrificiales", a diferencia de la manifiesta conjunción de «nombre» + «acción sacrificial» en las prácticas sacrificiales de substitución "a través de la denominación". A tal conclusión inducen aquellos testimonios que verifican la valoración de la figuración de la forma, únicamente, como símbolo de referencia del animal prescrito y no como su substituto: así, por ejemplo, en aquellos casos en los que el rechazo ético del sacrificio cruento debía impedir la representación veraz de la muerte de la víctima simulada (entre pitagóricos o hindúes); o también en el caso de prescripciones rituales en las que la representación plástica del animal sacrificial se convertía, precisamente por su carácter obligatorio, en un símbolo adecuado al rito o a la divinidad y no en un subterfugio (quizá los testimonios de la manzana y del pepino travestidos de animales, o el de los panes con forma de ciervo, de buey, de cerdo o de otros animales). En este sentido, es interesante recordar aquella ocasión -referida por Plutarco y Apiano- en la que los habitantes de Cícico se vieron obligados a modelar una ternera negra para Proserpina (puesto que no disponian de ella) que no sirvió para realizar el sacrificio sino para atraer a la víctima real requerida (vid. $\mathrm{n}$. 48).

La información etnográfica sobre la substitución de víctimas mediante la imitación de la forma se reduce a los testimonios proporcionados por los pueblos árticos y por los Saoras de India; pero, lamentablemente, poseemos escasos y poco consistentes datos de observación en esos ambientes, lo que dificulta su interpretación como casos de pretendidas substituciones sacrificiales ( $y$ no, por ejemplo, como la ofrenda del animal simbólico en el primer caso, y como un especial rito local en el segundo), 
así como respecto de un particular tratamiento sacrificial de las figuras zoomorfas, no atestiguado ${ }^{110}$.

Es indudable, sin embargo, que la "ductilidad" o el carácter "manipulable» de la materia de modelación de las "víctimas" simuladas podia crear un referente importante, y quizá necesario, respecto de su posibilidad de "ser sacrificadas" (como de hecho sucedía en las prácticas de carácter mágico). Nuestra insistencia en tales características físicas se deriva del convencimiento de que las representaciones de animales en arcilla o con metales -es decir, con materiales duros, no perecederos- que se ofrecían en diversos santuarios del mundo antiguo y que han sido interpretados generalmente como "substituciones" de víctimas animales eran, por el contrario, ex-votos, «intratables" sacrificialmente, que simbolizaban la permanencia de un sacrificio realizado, su eterna conmemoración y la de la piedad del oferente privado (permitiéndole, además, su ostentación a través del arte figurativo). La representación duradera, seguramente, no se debía percibir simplemente como substitución de una acción vinculada a una ocasión y tiempo restringidos como lo era el hecho espacial y temporal del sacrificio de una víctima animal ofrecido por un particular a una determinada divinidad; su carácter "eterno" debía añadir una permanencia de "efectos" - derivados, eso sí, de la acción sacrificial- que se sitúan en la esfera religiosa y también en la socio-cultural: se trataría -en estos casos- de una representación simbólica, pues, y no de un substituto sacrificial que, en tantos casos, poseería un coste en nada despreciable respecto al de la víctima animal real representada ${ }^{111 .}$

Servio alude indistintamente - como si fueran intercambiables- a dos materias de modelación, el pan y la cera; inútil es, pues, insistir en valencias "agrarias" y/o "mágicas" deducibles, respectivamente, de tales materias para descubrir los casos rituales a los que el gramático se refería con su testimonio sobre las prácticas de substitución en el sacrificio. Por otro lado, las interpretaciones tardias (proporcionadas por las fuentes clásicas) respecto de los ritos (seguramente no conocidos) que incluían tales prácticas de "substitución" sacrificial se inclinaban, como se recordará, por la motivación económica de pobreza de los oferentes (basándose seguramente

110 Confróntese con el caso del otro método de substitución, a través de la denominación y del tratamiento sacrificial simulados, atestiguado también entre los Saoras: vid. n. 80 .

"11 Al menos en el mundo mediterráneo antiguo y en la línea de interpretación "no sacrificial" de F.T. van StRATEN, "Gifts for the Gods", H.S. VerSnel (ed.), Faith, Hope and Worship. Aspects of religious Mentality in the Ancient World, Leiden 1981, 87-88, si bien este autor deja abierta la posibilidad de un uso efectivo de tales substitutos, no perecederos, en el sacrificio. 
en el escaso valor del substituto) o por la «no disponibilidad» accidental de la víctima requerida en una determinada ocasión que, ritualizada, permitía la construcción de un relato etiológico de la institución, en un determinado culto, de la solución del substituto animal. La dificultad y/o la imposibilidad de encontrar la víctima sacrificial, que el gramático arguye como motivo de dichas prácticas de substitución, no se adecúan ni a las líneas de interpretación citadas, ni —según se estableció- a una intención discursiva de tipo ético.

Es cierto, sin embargo, que alguna dificultad debió de generar la utilización de animales peligrosos o salvajes en determinados ritos del mundo clásico como, por ejemplo, las serpientes. El escoliasta de Luciano informa, precisamente, de la fabricación de serpientes falsas, dotadas de artificios mecánicos, por parte de los sacerdotes de Juno Sospita, cuando ya no se encontraban serpientes domesticadas para la celebración del peculiar ritual de Lanuvio: gracias a la oscuridad, puesto que el rito se desarrollaba en los subterráneos del santuario, no se podían descubrir esos artificios que, seguramente, daban movilidad a los animales simulados ${ }^{112}$; de oro eran las serpientes utilizadas en los ritos de iniciación a Sabazios mientras que se trataba de simples cuerdas - que eran despedazadas a imitación de la serpiente mítica destruida por Horus - en los misterios isíacos ${ }^{113}$... La semejanza de apariencia de los animales simulados con sus correspondientes reales hacía posible su uso ritual pero, como se advierte, no se trataba de unas substituciones en el sacrificio, ni de una simulación de víctimas ${ }^{114}$.

Para ilustrar el motivo de la dificultad/imposibilidad, que generaba la solución ritual de la simulación de lo real, Servio cita un par de ejemplos: pero estos tampoco se refieren a víctimas sacrificiales substituidas sino a casos de una simulación de elementos rituales ciertamente difíciles de procurarse: "sparserat et latices simulatos fontis Averni. nam et in templo Isidis aqua sparsa de Nilo esse dicebatur" ${ }^{115}$. Sin proponérselo, Servio 51.

112 Prop. IV.8.3 ss. y escolio a Luciano, DMort. 1.2, citados por G. BODEI GIGLIONI, cit. (n. 11)

113 Arnob., nat. V.21 y Plu., Moralia 358 CD (citados por C.A. LOBECK, cit. - n. $13-119$ y usados por G. CAPDEVILLE, cit. -n. 19-298).

114 El caso -único en su género en ámbito romano- de la cervaria ovis que era inmolada, según Festo-Paulo (49 y 57 L.), en substitución de una cierva y el caso análogo del sacrificio de una oveja antibous ("como si fuera o en lugar de un buey") a Atenea Polias, atestiguado por el calendario sacrificial de Erquia (vid. M. JAMESON, cit. -n. 31-156-158), podrian interpretarse como casos de una equivalencia de valor sin que ello implicase, quizá, una "substitución" de víctimas.

115 Serv, Aen. II.116.30-32 y IV.512 (ed. Harvard). Remito a mi artículo, cit. (n. 12) 237-243 para el estudio e información exhaustiva sobre ambos ejemplos. 
documenta en un mismo comentario, cuyo argumento es precisamente la simulación en el ámbito religioso, los dos modos (que hemos definido y establecido a través de la presentación de variados ejemplos) para llevar a cabo una substitución válida ritualmente en el ámbito de las prescripciones romanas. Pero, mientras que no parece ser capaz de añadir algún ejemplo concreto del principio de la figuración de la forma o del mantenimiento de la apariencia en la substitución «in sacris", son dos los que "recuerda» del modo de simulación a través de la denominación: se decía que "era» agua del Nilo, o agua de la fuente del Averno, se entiende, al agua corriente.

La imposibilidad o la dificultad de cumplir con aquellas prescripciones rituales dominadas por un localismo, puesto que generaban importantes desplazamientos geográficos, está suficientemente atestiguada en ámbito histórico-religioso. El recurso a la recreación de ambientes, lugares o elementos difíciles de alcanzar o encontrar a través de la utilización de un lenguaje representativo (por ejemplo, el topónimo religioso transferido ritualmente) se halla ampliamente atestiguado. Además de los casos del Nilo y del Averno, Servio informaba (en otro pasaje) que se podía crear ficticiamente un "lugar romano" en las provincias para el augurium, de modo que el general del ejército no tuviera que ausentarse para renovar los auspicios en Roma ${ }^{116}$; también en ámbito provincial, y puesto que el baño ritual de la diosa Cibeles debía tener lugar en el río Almón romano, cuando se celebraba su fiesta en las colonias "Almonem fluvium simulari dicit»" 117; o, por citar otro tipo de ejemplos, la obligación de la peregrinación a lugares sagrados distantes inducía en ciertas ocasiones, condicionadas por la dificultad o la imposibilidad de realizarla realmente, a recrear en una elegida proximidad dicho lugar; asi, entre los hindúes se puede substituir el lugar de peregrinaje por excelencia, el Ganges, por cualquier otro curso de agua siempre que con el pensamiento se evoque el río sagrado ${ }^{118}$; y entre los Hopi de Nuevo México, en caso de lejanía de un determinado santuario que ha de ser visitado, se puede denominar con el nombre del santuario lejano uno cercano a la aldea ${ }^{119} \ldots$

Un caso especial de substitución "ritualizada" de un elemento sagrado, y por tanto en toda ocasión necesaria, es el proporcionado por la planta- Soma del antiguo vedismo. Posiblemente la planta original era desconocida, o frecuentemente no disponible (o incluso, quizá, nunca

116 Serv., Aen. Il.178 (ed. Harvard).

117 Ambr., Ep. ad Valent. c. Symm. V. Ep. 32 (citado por C.A. LOBECK, cit. -n.13-119).

118 A.-M. Esnout, cit. (n. 65) 98.

119 E.C. Parsons, Pueblo Indian Religion, Chicago 1939, 1148. 
existió): la efectiva inaccesibilidad ritual, traducida en una imposibilidad práctica de su uso, generaba su sistemática substitución por la planta$p \bar{u} t i k \bar{a}$ u otras; pero durante el rito en que tales plantas eran usadas recibian la denominación de "Soma»" 120 .

El agua de ríos distantes, los lugares lejanos, las plantas cuyo hallazgo crea dificultades... son elementos prescritos y obligatorios para determinados ritos, si bien su ocasional o frecuente imposibilidad de acopio por parte del oferente privado "permitía»su substitución: manteniéndose las características de los originales, los substitutos reciben los nombres que permiten evocar los elementos reales difíciles o imposibles de alcanzar y de presentar en los ritos.

Es interesante señalar la ausencia en el discurso sobre la simulación en el sacrificio construido por Servio de una explícita alusión a la conocida tradición romana de la interpretación ética de ciertos ritos como casos de substitución de antiguos sacrificios humanos; y sorprende porque, en tal tradición, los relatos etiológicos de las substituciones sacrificiales se basaban, precisamente, en una "astucia" lingüística, en una homonimia que determinaba la validez de la substitución y su aceptación ritual por la divinidad (casos, por ejemplo, del origen de la substitución de hombres por velas en las Saturnalia, o el del rito de expiación de los rayos mediante las cabezas exigidas por Júpiter Elicio a Numa, que las substituye jugando con una triple sonoridad de palabras, o el de los Compitalia, con la substitución de cabezas humanas por las de ajos o amapolas) y que eran suficientemente conocidos por los autores tardíos interesados en ritos y tradiciones pasadas y por su ética ${ }^{121} \ldots$

Por otra parte, la inexactitud de la consideración del "sacrificio substituido" como argumento del pasaje serviano se aprecia por los ejemplos que el autor aduce: su lección informativa era, indudablemente, que el oferente podía acudir a la simulación de aquellos elementos que se exigían en el cumplimiento de un ritual; $y$, además, que simular "válidamente» era imitar la figura o el nombre de la realidad substituida. Es posible, pues, que su discurso fuese una interpretación genérica de la simulación ritual, basada en el conocimiento de ciertas prácticas cultuales romanas interpretadas, desde tanto tiempo atrás, como substitutivas (a las enunciadas anteriormente se podrían añadir las de tipo "figurativo" como los Sigillaria

120 B.K. SMITH-W. DONIGER, cit. (n. 53) 204 y n. 36.

124 Consúltense J. GAGÉ, «Pyrrus el l'influence religieuse de Dodone», RHR 146, 1954, 32-37 y D. PORTE, L'étiologie religieuse dans les Fastes d'Ovide, Paris, 1985, 128, 131-139 y $179-190$ (con fuentes). 
- los Argea...); pero a ella superpone una «explicación» (quizá más personal) que restringe la información al ámbito de la dificultad y de la imposibilidad en el cumplimiento de las prescripciones rituales como motivo de simulación y substitución de elementos: las de ciertos animales y materias exigidos por determinados ritos.

Según la comparación establecida por la información histórico-religiosa expuesta, tales motivos eran aducidos para explicar ciertas prácticas de simulación de formas en el sacrificio (casos de la manzana o del pepino travestidos), mientras que referidos a usos rituales explicaban determinadas prácticas de substitución conceptual en el sacrificio (en el vedismo el caso de la planta-Soma; en el judaísmo el caso del relato de sacrificios). La interpretación dual de Servio (relativa a ambos modos de substitución) se halla, por tanto, en un nivel correcto de comprensión del "fenómeno" de las substituciones, aun cuando se puedan apreciar significativas diferencias respecto del contexto en que estas se producian; y así, el segundo modo de substitución es ilustrado por Servio mediante la referencia a ritos de representación y no - como se ha señalado respecto de otras tradiciones romanas de substitución- de sacrificios.

Respecto del primer modo de substitución a través de la figura, la comparación histórico-religiosa ha demostrado que la representación de las "víctimas" animales poseía, fundamentalmente, una valencia simbólica (más que la esperada sacrificial) que determinaba su posibilidad de utilización ritual (y no estrictamente sacrificial) en substitución del animal real o, simplemente, como posible ofrenda simbólica referencial. En cuanto a su interpretación, sin embargo, la simulación de la figura de las "víctimas" se entendía como una necesidad ritual (caso de la señalada imposibilidad de ofrenda de la víctima prescrita) o provocada por una imposibilidad económica del oferente. Servio parece «interpretar» este modelo de substitución apoyándose en una lógica de la dificultad en el cumplimiento que parece combinar la imposibilidad económica, quizá (“quae exhiberi non poterant»: vid. n. 12), con la imposibilidad de encontrar el animal prescrito.

En ámbito romano, sin embargo, los posibles ejemplos de estas prácticas y de tales motivaciones no se encuentran, frente a lo esperado, en un contexto de substitución en el sacrificio (panes zoomórficos, caso de las serpientes) sino, más probablemente, en ese contexto del comportamiento cultual privado que recurría a la simulación de la apariencia como medio de ahorro o de superación de dificultades concretas: así, por ejemplo, las soluciones domésticas relativas a las ofrendas aromáticas que substituían al incienso... 
Un tipo de comportamiento cultual que tiende a reducir los gastos relativos a los «pequeños» elementos del rito (y no en los sacrificios como interpreta "genéricamente" Servio) es atestiguable en ámbito histórico-religioso comparado. Por citar un par de ejemplos "distantes", señalaremos el caso de la substitución de la típica libación de cerveza sobre la tumba de los antepasados, y en acción de gracias por la cosecha, por una realizada con agua teñida de amarillo entre las familias pobres de los Bavenda ${ }^{122}$, mientras que la gente de Okinawa, de religión sintoísta, substituye el vino por el té en los ritos domésticos destinados a los espíritus kami, en interés de la economía ${ }^{123}$.

Se percibe, así, una interesante diferencia de método y de concepto entre el pequeño ahorro privado en el culto, que acude a la simulación de la apariencia, y el "ahorro" situado en un contexto ritual, basado en una "suficiencia ritualizada", que recurre a formas más complejas de substitución a través del lenguaje y de la acción rituales.

En conclusión, el testimonio de Servio se halla en esta línea de interpretación genérica de la posibilidad de simulación en el sacrificio, si bien los datos concretos que proporciona se refieran a estas dificultades privadas en el cumplimiento cultual resueltas mediante la apariencia. A nivel privado, pues, el oferente romano ( $y$ el de otros ambientes religiosos) afrontaba con piadosa intención el cumplimiento de las prescripciones rituales, como deber religioso, si bien su economía podía imponer o servirse de la posibilidad de ahorrar, también piadosamente, a través de una simulación de apariencias; y así, la validez ritual, lograda de tal modo, suscitaría una espontánea institución cultual de "especiales" ofrendas a la medida de quien deseaba cumplir, suficientemente, con la divinidad.

122 H. A. Stayt, The Bavenda, Oxford 1931, 257-258.

123 W. P. LebrA, Okinawan Religion. Belief, Ritual and Social Structure, Hawai 1966, 66. 